e-Jurnal Ilmiah BIOSAINTROPIS (BIOSCIENCE-TROPIC)

Volume 6/ No.: 1 / Halaman 46 - 53 / Agustus Tahun 2020

ISSN :2460-9455 (e) - 2338-2805(p)

\title{
Analisis Keanekaragaman Tumbuhan Invasif Di Kawasan Hutan Pantai Balekambang Desa Srigonco Kecamatan Bantur Kabupaten Malang
}

\section{The Diversity Analysis of Invasive Plant in Balekambang Beach Forest Area, Srigonco Village, Bantur District, Malang Regency}

\author{
Miftahul Mukarromah ${ }^{1 *}$, Ari Hayati $^{\left.2^{* *}\right)}$, Hasan Zayadi ${ }^{3}$ \\ ${ }^{123}$ Jurusan Biologi Fakulltas Matematika dan Ilmu Pengetahuan Alam Universitas Islam Malang, Indonesia
}

\begin{abstract}
ABSTRAK
Pantai Balekambang adalah destinasi wisata alam pantai di Kabupaten Malang yang paling banyak dikunjungi hingga akhir tahun 2015.Salah satu jalur invasi dari tumbuhan invasif adalah Tourism (Wisata). Tujuan dari penelitian ini adalah mengidentifikasi jenis tumbuhan invasif, keanekaragaman dan membandingkan nilai indeks keanekaragaman dengan faktor abiotik. Metode penelitian ini deskriptif dengan tehnik pengambilan sampling secara sistematis menggunakan Belt Transect, dan pengukuran faktor abiotik meliputi faktor edafik dan faktor mikro klimatik. Jenis spesies tumbuhan asing invasif yang terdapat di hutan pantai Balekambang diidentifikasi sebanyak tujuh belas spesies yaitu Hemighraphis glaucescens, Oplismenus sp, Amomum coccineum, Arenga obtusifolia, Leucaena leucochephana, Mimosa sp, Cassia siamea, Eupatorium odoratum, Hyptis capitata, Cynodon dactylon, Sida rhombifolia, Synedrella nudiflora.Chromolaena odorata, Leucaena leucochepala, Mimosa pudica, dan Ruellia tuberose dengan nilai indeks keanekaragaman tumbuhan invasif pada hutan lindung dan produksi tergolong tinggi dibanding mangrove. Hasil analisis uji korelasi nilai indeks keanekaragaman dengan faktor abiotik menunjukkan arah positif $(+)$ pada salinitas tanah dimana nilai R2 sebesar 0.5606 atau 50\%, yang artinya menunjukkan hubungan antara salinitas tanah dengan kelimpahan tumbuhan invasif di kawasan hutan pantai Balekambang sebesar 50\%.
\end{abstract}

Kata kunci: tumbuhan invasif, pantai Balekambang, belt transect, keanekaragaman

\section{ABSTRACT}

Balekambang Beach is the most visited beach destination in Malang Regency until the end of 2015. One of the invasive pathways of invasive plants is Tourism. The purpose of this study was to identify invasive plant species, diversity and compare the value of the diversity index with abiotic factors. This research method is descriptive with systematic sampling techniques using Belt Transect, and measurements of abiotic factors include edafic factors and climatic micro factors. Invasive alien plant species found in the Balekambang coastal forest are identified as seventeen species namely (ㅂemighraphis glaucescens), (ㅁplismenus sp), (Amomum coccineum), (Arenga obtusifolia), (Leucaena leucochephana), (Mimosa sp), (Cassia siamea), (Eupatorium odoratum), ( Hyptis capitata), (Cynodon dactylon), ( Sida rhombifolia), (Synedrella nudiflora), (Chromolaena odorata), (Leucaena leucochepala), (Mimosa pudica), and (Ruellia tuberosa) with the index value of invasive plant diversity in protected forests and production classified as high compared to mangroves. The results of the diversity index value with abiotic factors showed a positive (+) direction on soil sailinity where the R2 value was 0.5606 or $50 \%$, which means it showed a relationship between soil salinity and an abundance of invasive plants in Balekambang coastal forest area of $50 \%$.

Keywords:invasive plants, Balekambang beach, belt transect, diversity

\footnotetext{
${ }^{*}$ Miftahul Mukarromah, Jurusan Biologi FMIPA UNISMA, J1. MT Haryono 193, Malang 65144 Telp. 085806006318 e-mail:mukarromah.miftah@gmail.com

${ }^{* *}$ Dr. Dra. Ari Hayati. M.P. Jurusan Biologi FMIPA UNISMA, J1. MT Haryono 193, Malang 65144

Telp.0895335403837.E-mail:aridanial29@yahoo.com
}

Diterima Tanggal 27 Juli 2019 - Dipublikasikan Tanggal 25 Agustus 2020 
e-Jurnal Ilmiah BIOSAINTROPIS (BIOSCIENCE-TROPIC)

Volume 6/ No.: 1 / Halaman 46 - 53 / Agustus Tahun 2020

ISSN :2460-9455 (e) - 2338-2805(p)

\section{Pendahuluan}

Diketahui Keanekaragaman ekosistem di Indonesia sangat berakenaragam dan sekitar 74 tipe vegetasi membentuk formasi satu dengan yang lain, sehingga Indonesia sangat kaya akan Keanekaragaman hayati nya. Variasi ekosistem tersebut menunjukkan bahwa setiap ekosistem kaya akan kekayaan jumlah jenis flora dan fauna [1].

Kabupaten Malang merupakan salah satu daerah yang memiliki banyak potensi wisata alam. Terdapat 144 destinasi wisata di Kabupaten Malang dan sebanyak 20 destinasi adalah wisata alam pantai. Destinasi wisata alam pantai di Kabupaten Malang yang paling banyak dikunjungi hingga akhir tahun 2015 adalah Pantai Balekambang [2].

Spesies invasif adalah spesies yang tumbuh bukan pada habitat alaminya namun mampu tumbuh menyebar dengan cepat dan mengganggu komunitas asli pada suatu tempat.Invasif cenderung memiliki efek yang merugikan [3].

Hutan pada kawasan pantai Balekambang berbatasan langsung dengan jalan raya dan pantai Balekambang, yang merupakan destinasi wisata paling banyak dikunjungi oleh wisatawan serta pemukiman penduduk, membuat hutan pantai Balekambang sangat rentan terhadap pengaruh aktivitas manusia. Pengaruh aktifitas manusia tersebut menandakan adanya peluang terjadinya penyebaran tumbuhan-tumbuhan asing yang berpotensi menginvasi kawasan tersebut sehingga merubah fungsi dari hutan tersebut.

Penelitian ini bertujuan untuk mengidentifikasi jenis tumbuhan invasif, keanekaragaman dan membandingkan nilai indeks keanekaragaman dengan faktor abiotik.

\section{Material dan Metode}

\section{Bahan dan Alat}

Bahan yang digunakan dalam penelitian ini adalah tumbuhan invasif di kawasan hutan pantai Balekambang.

Alat yang digunakan dalam penelitian ini adalah alat tulis, buku identifikasi, GPS (Global Positioning System), Kamera, Kertas Label, Luxmeter, Meteran, Gunting, Penggaris, Pisau, Plastik Spesimen, Tali raffia, Termohigrometer, Termometer, Soil tester, Induksi Elektromagnetik (EM38), Luxmeter, dan Anemometer.

\section{Metode}

Metode penelitian ini deksriptif dengan tehnik pengambilan sampling secara sistematis menggunakan Belt Transect dengan peletakan petak contoh dilakukan secara Systematic with random start. Petak ukur yang digunakan berbentuk persegi empat yang dibuat secara bertingkat/bersarang (nested sampling) untuk mengetahui kondisi vegetasi pada masing-masing tingkat pertumbuhan (semai, pancang, tiang dan pohon).

Komunitas yang dianalisis terdiri atas 3 stasiun yaitu hutan lindung $(102,6 \mathrm{Ha})$ menggunakaan Intensitas Sampling (IS) 1\% dengan jumlah plot sebanyak 26 plot. Hutan produksi (11.81 Ha) menggunakan Intensitas Sampling (IS) 5\% sehingga plot pengamatan sebanyak 15 plot, dan 8 plot pada Mangrove (6.42 Ha) menggunakan Intensitas Sampling (IS) 5\%, sehingga total keseluruhan plot pengamatan sebanyak 49 plot. Penempatan plot berada pada kanan kiri jalur dengan lebar jalur $40 \mathrm{~m}$ dan panjang jalur $1000 \mathrm{~m}$ atau $1 \mathrm{~km}$. Jalur pengamatan diletakkan memotong kontur atau topografi dengan asumsi keterwakilan kondisi hutan yang diteliti. Pengukuran faktor abiotik diukur pada setiap stasiun, dimana pengukuran faktor edafik meliputi suhu, kelembaban, $\mathrm{pH}$ dan salinitas tanah. Sedangkan pengukuran faktor mikro klimatik meliputi intensitas cahaya, kecepatan angin, suhu dan kelembaban udara. 
e-Jurnal Ilmiah BIOSAINTROPIS (BIOSCIENCE-TROPIC)

Volume 6/ No.: 1 / Halaman 46 - 53 / Agustus Tahun 2020

ISSN :2460-9455 (e) - 2338-2805(p)

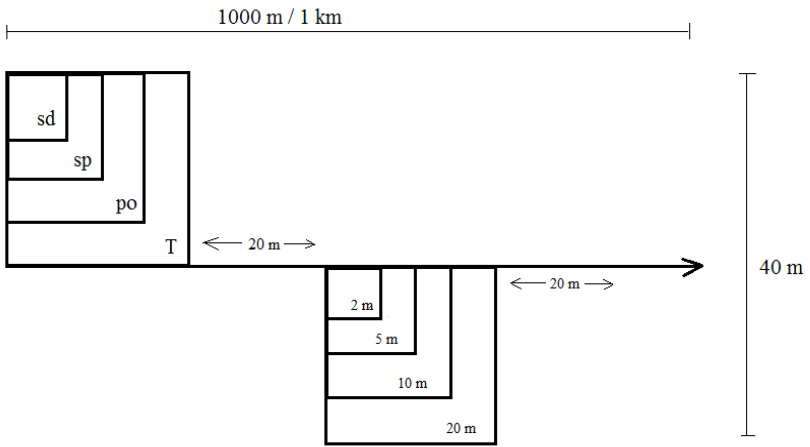

\section{Gambar 1. Petak Contoh}

Petak ukur berukuran $20 \times 20 \mathrm{~m}$, kemudian dibuat bertingkat dengan ukuran plot pengambilan data untuk tingkat Semai ( $2 \mathrm{~m} \times 2 \mathrm{~m})$, Pancang $(5 \mathrm{~m} \times 5 \mathrm{~m})$, Tiang $(10 \mathrm{~m} \times 10 \mathrm{~m})$ dan Pohon $(20 \mathrm{~m} \times$ $20 \mathrm{~m})[4]$.

Keterangan [4] :

- Semai adalah anakan pohon mulai kecambah sampai setinggi $<1,5$ meter.

- Pancang adalah anakan pohon yang tingginya1,5 $\mathrm{cm}$ dan diameter $<7 \mathrm{~cm}$.

- Tiang adalah pohon muda dengan keliling $<36 \mathrm{~cm}$.

- Pohon adalah pohon dewasa dengan keliling $>36 \mathrm{~cm}$.

Indeks keanekaragaman yang didapat dihitung dengan menggunakan rumus indeks keanekaragaman Shannon-Wiener sebagai berikut [4].

$$
\mathbf{H}^{\prime}=-\Sigma p_{i} \ln \mathbf{p}_{i}
$$

dimana, $\mathrm{p}_{i}=\mathrm{n}_{\mathrm{i}} / \mathrm{N}$

Keterangan :

H': Nilai dari Indeks keanekaragaman Shannon-Wiener

$\mathrm{P}_{\mathrm{i}}$ : Perbandingan jumlah individu suatu jenis dengan jumlah individu keseluruhan

$\mathrm{n}_{\mathrm{i}}$ :Nilai INP suatu jenis.

$\mathrm{N}$ : Nilai INP individu keseluruhan .

Besar kecil dari nilai indeks keanekaragaman Shannon Wiener dinyatakan sebagai berikut [4]:

1. Nilai $\mathrm{H}^{\prime}<1$ menunjukkan keanekaragaman jenis rendah.

2. Nilai H' $1 \leq \mathrm{H}^{\prime} \leq 3$ menunjukkan keanekaragaman spesies sedang.

3. Nilai H'> 3 menunjukkan keanekaragaman spesies tinggi. 
e-Jurnal Ilmiah BIOSAINTROPIS (BIOSCIENCE-TROPIC)

Volume 6/ No.: 1 / Halaman 46 - 53 / Agustus Tahun 2020

ISSN :2460-9455 (e) - 2338-2805(p)

Faktor edafik yang diukur meliputi kelembaban dan suhu tanah menggunakan termohigrometer, $\mathrm{pH}$ tanah menggunakan soil $\mathrm{pH}$ Meter dan salinitas tanah diukur menggunakan alat Induksi Elektromagnetik (EM38). Faktor mikro klimatik yang diukur meliputi Suhu udara serta kelembaban udara diukur menggunakan alat Termohigrometer. Pengukuran Intensitas Cahaya menggunakan alat Luxmeter dan kecepatan angin menggunakan alat Anemometer. Hasil pengukuran faktor abiotik kemudian diuji faktor korelasi dengan nilai indeks keanekaragaman yang didapat dengan Ms. Excel.

\section{Hasil dan Diskusi}

Identifikasi Spesies Tumbuhan Asing Invasif: Berdasarkan hasil identifikasi, diketahui sebanyak 12 spesies dari 8 famili tumbuhan invasif di Hutan pantai balekambang meliputi hutan lindung, hutan produksi dan mangrove. Selain 12 spesies yang ditemukan didalam plot penelitian, terdapat tumbuhan invasif yang ditemukan di luar petak penelitian yang berjumlah 5 spesies dari 3 famili sehingga jumlah total tumbuhan asing invasif berjumlah 17 spesies.

Tabel 1. Spesies Tumbuhan Asing Invasif Di Kawasan Hutan Pantai Balekambang

\begin{tabular}{|c|c|c|c|}
\hline No. & Spesies & Famili & Habitus \\
\hline \multicolumn{4}{|c|}{ didalam petak analisis vegetasi } \\
\hline 1 & Hemigraphis glaucescens $^{2), 3)}$ & Acanthaceae & Semak \\
\hline 2 & Oplismenus $s p^{3)}$ & Poaceae & Semak \\
\hline 3 & Amomum coccineum ${ }^{3)}$ & Zingiberaceae & Herba \\
\hline 4 & Arenga obtusifolia ${ }^{1), 2)}$ & Arecaceae & Pohon \\
\hline 5 & Leucaena lechocephana ${ }^{3)}$ & Fabaceae & Semak \\
\hline 6 & Mimosa $s p^{1), 2)}$ & Fabaceae & Semak \\
\hline 7 & Cassia siamea $^{1), 2), 3)}$ & Fabaceae & Semak \\
\hline 8 & Eupatorium odoratum $^{1)}$ & Asteraceae & Semak \\
\hline 9 & Hyptis capitata ${ }^{2}$ & Lamiaceae & Semak \\
\hline 10 & Cynodon dactylon ${ }^{2), 3)}$ & Poaceae & Semak \\
\hline 11 & Sida rhombifolia ${ }^{2), 3)}$ & Malvaceae & Semak \\
\hline 12 & Synedrella nudiflora ${ }^{1), 2), 3)}$ & Asteraceae & Semak \\
\hline No. & \multicolumn{3}{|c|}{ di luar petak analisis vegetasi } \\
\hline 1 & Chromolaena odorata $^{2)}$ & Asteraeae & Semak \\
\hline 2 & Leucaena leucocephala ${ }^{2), 3)}$ & Fabaceae & Semak \\
\hline 3 & Mimosa pudica ${ }^{3)}$ & Fabaceae & Semak \\
\hline 4 & Ruellia tuberose $^{3)}$ & Acanthaceae & Semak \\
\hline 5 & Synedrella nudiflora ${ }^{1), 2), 3)}$ & Asteraeae & Semak \\
\hline
\end{tabular}

Keterangan $:{ }^{1}[5],{ }^{2)}[6],{ }^{3)}[7]$

Jenis tumbuhan invasif yang berhasil teridentifikasi di hutan pantai balekambang terdiri dari 17 spesies dari 8 famili yang sebagian besar habitus dari spesies asing invasif yaitu semak. Hal ini dikarenakan tumbuhan ber habitus semak lebih mudah menyebar, pertumbuhan cepat, pengkolonisasi 
e-Jurnal Ilmiah BIOSAINTROPIS (BIOSCIENCE-TROPIC)

Volume 6/ No.: 1 / Halaman 46 - 53 / Agustus Tahun 2020

ISSN :2460-9455 (e) - 2338-2805(p)

pada daerah cepat dan organ perkembangbiakan seperti biji lebih mudah terbawa hewan ataupun manusia.

Keanekaragaman Tumbuhan Invasif: Berdasarkan hasil penelitian pada hutan lindung, diidentifikasi tumbuhan invasif sebanyak 4 spesies dari 4 famili, yaitu Hemigraphis glaucescens, Oplismenus sp, Amomum coccineum dan Arenga obtusifolia. Hasil penghitungan indeks kenekaragaman pada hutan lindung dapat dilihat dalam Tabel 2.

Tabel 2. Nilai Indeks Keanekaragaman Tumbuhan Invasif di Hutan Lindung

\begin{tabular}{llcccc}
\hline \multicolumn{1}{c}{ Spesies } & \multicolumn{1}{c}{ Famili } & Jumlah & Pi & Ln Pi & Pi Ln Pi \\
\hline Hemigraphis glaucescens & Acanthaceae & 31 & 0,29245 & $-1,2295$ & $-0,3596$ \\
Oplismenus sp & Poaceae & 35 & 0,33019 & $-1,1081$ & $-0,3659$ \\
Amomum coccineum & Zingiberaceae & 10 & 0,09434 & $-2,3609$ & $-0,2227$ \\
Arenga obtusifolia & Arecaceae & 30 & 0,28302 & $-1,2622$ & $-0,3572$ \\
\hline \multirow{2}{*}{ Jumlah } & & \multirow{2}{*}{$\mathbf{1 0 6}$} & & & $\mathbf{- 1 , 3 0 5 4}$ \\
& & & & & $\mathbf{H}: \mathbf{1 , 3 0 5 4}$ \\
\hline
\end{tabular}

Berdasarkan hasil penghitungan indeks keanekaragaman Shanon-Wiener (H') dapat diketahui keanekaragaman spesies tumbuhan asing invasif pada hutan lindung sebesar 1,3054 yang tergolong dalam keanekaragaman sedang. Diketahui Oplismenus sp memiliki jumlah tertinggi yakni 35 spesies. Dikutip dari penelitian Sahira (2016) diketahui bahwa kelimpahan jenis Oplismenus sp juga ditemukan di kawasan taman hutan raya dr. Moh. Hatta, Padang, Sumatera Barat. Menurut Setyawati (2015) Oplismenus sp adalah tanaman abadi berbunga dari keluarga Poaceae, dianggap asli di Amerika Serikat bagian tenggara. Oplismenus sp dapat ditemukan di setiap benua di dunia kecuali Antartika, tumbuh terutama di daerah tropis dan subtropis pesisir serta pulau tropis dan subtropis. Oplismenus sp mempunyai biji lengket yang dapat melekat pada bulu dan pakaian sehingga mudah didistribusikan oleh hewan maupun manusia.

Berdasarkan hasil penelitian pada hutan produksi, di identifikasi sebanyak 7 spesies dari 5 famili, yaitu Leucaena leuchocephana, Mimosa sp, Cassia siamea, Eupatorium odoratum, Hyptis capitata, Cynodon dactylon dan Sida rhombifolia. Hasil penghitungan indeks kenekaragaman pada hutan produksi dapat dilihat dalam Tabel 3.

Tabel 3. Nilai Indeks Keanekaragaman Tumbuhan Invasif di Hutan Produksi

\begin{tabular}{|c|c|c|c|c|c|}
\hline Spesies & Famili & Jumlah & $\mathbf{P i}$ & Ln Pi & Pi Ln Pi \\
\hline Leucaena lechocephana & Fabaceae & 30 & 0,38462 & $-0,9555$ & $-0,3675$ \\
\hline Mimosa sp & Fabaceae & 31 & 0,39744 & $-0,9227$ & $-0,3667$ \\
\hline Cassia siamea & Fabaceae & 2 & 0,02564 & $-3,6636$ & $-0,0939$ \\
\hline Eupatorium odoratum & Asteraceae & 5 & 0,0641 & $-2,7473$ & $-0,1761$ \\
\hline Hyptis capitata & Lamiaceae & 3 & 0,03846 & $-3,2581$ & $-0,1253$ \\
\hline Cynodon dactylon & Poaceae & 5 & 0,0641 & $-2,7473$ & $-0,1761$ \\
\hline Sida rhombifolia & Malvaceae & 2 & 0,02564 & $-3,6636$ & $-0,0939$ \\
\hline Jumlah & & 78 & & & $\begin{array}{c}-1,3996 \\
H^{\prime}: 1,3996\end{array}$ \\
\hline
\end{tabular}


e-Jurnal Ilmiah BIOSAINTROPIS (BIOSCIENCE-TROPIC)

Volume 6/ No.: 1 / Halaman 46 - 53 / Agustus Tahun 2020

ISSN :2460-9455 (e) - 2338-2805(p)

Berdasarkan hasil penghitungan indeks keanekaragaman Shanon-Wiener (H') dapat diketahui keanekaragaman spesies tumbuhan asing invasif pada hutan produksi sebesar 1,3996 yang tergolong dalam keanekaragaman sedang. Diketahui Mimosa sp memiliki jumlah tertinggi yakni 31 spesies. Dikutip pada Abywijaya (2014) persebaran dari Mimosa sp juga ditemukan pada cagar alam pulau Sempu. Mimosa sp. adalah spesies tumbuhan yang berasal dari Amerika Tropis. Mimosa sp. merupakan spesies intoleran, dapat menghasilkan menghasilkan 675 biji per tahun (Ajorlo et al. 2014). Di Pulau Jawa dapat ditemukan pada ketinggian 1-1200 m. Spesies ini berbunga sepanjang tahun dan hanya bereproduksi melalui biji (Ajorlo et al. 2014; SEAMEO BIOTROP 2008).

Berdasarkan hasil penelitian pada Mangrove, di identifikasi hanya 1 spesies saja dari 1 famili yakni Synedrella nodiflora. Hasil penghitungan indeks kenekaragaman pada vegetasi mangrove dapat dilihat dalam Tabel 4.

Tabel 4. Nilai Indeks Keanekaragaman Tumbuhan Invasif di Mangrove

\begin{tabular}{|c|c|c|c|c|c|}
\hline Jenis & Famili & Jumlah & $\mathbf{P i}$ & Ln Pi & Pi Ln Pi \\
\hline Synedrella nodiflora & Asteraceae & 100 & 1 & 0 & 0 \\
\hline Jumlah & & 100 & & & $\begin{array}{c}0 \\
H^{\prime}: 0\end{array}$ \\
\hline
\end{tabular}

Berdasarkan hasil penghitungan indeks keanekaragaman Shanon-Wiener ( $\left.\mathrm{H}^{\prime}\right)$ dapat diketahui keanekaragaman spesies tumbuhan asing invasif pada vegetasi mangrove sebesar 0 yang tergolong dalam keanekaragaman rendah. Kelimpahan Synedrella nudiflora juga ditemukan pada berbagai penelitian sebelumnya, seperti pada penelitian Yuliana \& Lekitoo (2018) di Manokwari Papua Barat, Utami \& Murningsih (2018) di Semarang Jawa Tengah banyak ditemukan persebaran dari Synedrella nodiflora. Dikutip dari Soerjani (1987), Synedrella nudiflora merupakan tumbuhan berasal dari Amerika Tropika, dapat hidup pada hutan terbuka, belukar di pinggir pedesaan, pagar, kebun tanaman (kopi dan kelapa), sepanjang jalan dan tanggul, pada lahan terabaikan, taman, dan padang rumput dan sering kali terlihat berkelompok. Serta dapat ditemukan hidup di ketinggian 0-1200 $\mathrm{m}$ dpl dan pada lahan dataran tinggi. Dari teori tersebut diketahui bahwa Synedrella nodiflora termasuk tumbuhan invasif yang persebaran dan kelimpahannya banyak ditemukan di Indonesia, termasuk di kawasan hutan pantai Balekambang.

Dari hasil diatas, diketahui kenekaragaman tumbuhan invasif di kawasan hutan pantai Balekambang sangat bervariasi, yang mana nilai indeks kenanekaragaman terendah terdapat dalam vegetasi Mangrove. Variasi keanekaragaman pada kawasan hutan pantai Balekambang sama seperti penelitian sebelumnya yang dikutip dari penelitian Zayadi dan Hayati (2017) tentang distribusi pohon peneduh jalan.

Edafik dan Faktor Klimatik: Berbagai jenis dan keanekaragaman tumbuhan invasif di kawasan hutan Balekambang tidak terlepas dari faktor edafik dan klimatik.Rata - rata pengukuran faktor edafik dan mikro klimatik dapat dilihat pada Tabel 5.

Setelah memperoleh data mengenai indeks keanekaragaman dan faktor abiotik pada kawasan hutan pantai Balekambang diperoleh maka langkah selanjutnya adalah melakukan uji korelasi. Dengan menggunakan program excel, uji korelasi dilakukan untuk mengetahui hubungan antara nilai indeks keanekaragaman dengan faktor abiotik di kawasan hutan pantai Balekambang. Hasil analisis uji korelasi nilai indeks keanekaragaman dengan faktor abiotik menunjukkan arah positif $(+)$ pada salinitas tanah dimana nilai R2 sebesar 0.5606 atau 50\%, yang artinya menunjukkan hubungan antara salinitas tanah dengan kelimpahan tumbuhan invasif di kawasan hutan pantai Balekambang sebesar $50 \%$ (Gambar 2). 
e-Jurnal Ilmiah BIOSAINTROPIS (BIOSCIENCE-TROPIC)

Volume 6/ No.: 1 / Halaman 46 - 53 / Agustus Tahun 2020

ISSN :2460-9455 (e) - 2338-2805(p)

Tabel 5. Nilai Indeks Keanekaragaman Tumbuhan Invasif di Hutan Produksi

\begin{tabular}{ccccc}
\hline No. & Faktor Abiotik & $\begin{array}{c}\text { Hutan Lindung } \\
\mathbf{H}^{\prime} \mathbf{:} \mathbf{1 , 3 0 5 4}\end{array}$ & $\begin{array}{c}\text { Hutan Produksi } \\
\mathbf{H}^{\prime}: \mathbf{1 , 3 9 9 6}\end{array}$ & $\begin{array}{c}\text { Mangrove } \\
\mathbf{H}^{\prime}: \mathbf{0}\end{array}$ \\
\hline 1 & Suhu Tanah & 27,67 & 27,33 & 27,91 \\
2 & Kelembaban Tanah & 52,33 & 38,33 & 66,33 \\
3 & pH Tanah & 7 & 7 & 7 \\
4 & Salinitas Tanah & 0,5 & 0,1 & 2 \\
5 & Suhu Udara & 27,83 & 27,9 & 27,71 \\
6 & Kelembaban Udara & 86,3 & 84,3 & 86 \\
7 & Intensitas Cahaya & 650,67 & 819,67 & 650 \\
8 & Kecepatan Angin & 0.33 & 0.01 & 0.03 \\
\hline
\end{tabular}

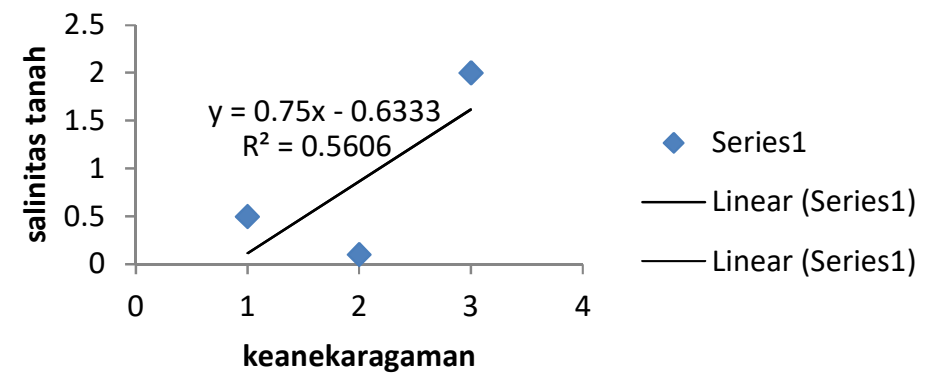

Gambar 2. Korelasi Salinitas Tanah Dengan Nilai Indeks Keanekaragaman

Banyak invasi yang berhasil ditentukan oleh karakter lingkungan dan sering didasarkan pada ketersediaan sumber daya alam seperti pada salinitas tanah [16]. Peningkatan ketersediaan sumber daya alam menuju terjadinya pertumbuhan populasi, memberikan kesempatan pada spesies yang menginvasi untuk mengkolonisasi dan mengubah suksesi.

\section{Kesimpulan}

Pada hutan pantai Balekambang, ditemukan tumbuhan invasif sebanyak 17 spesies dari 8 famili. Spesies tersebut adalah Hemighraphis glaucescens, Oplismenus sp, Amomum coccineum, Arenga obtusifolia, Leucaena leucochephana, Mimosa sp, Cassia siamea, Eupatorium odoratum, Hyptis capitata, Cynodon dactylon, Sida rhombifolia, dan Synedrella rhombifolia. Jenis asing invasif lainnya yang ditemukan di luar plot penelitian terdapat 5 spesies dari 3 famili. Spesies tersebut adalah Chromolaena odorata, Leucaena leucochepala, Mimosa pudica, Ruellia tuberose dan Synedrella nudiflora dengan nilai indeks keanekaragaman tumbuhan invasif pada hutan lindung dan produksi tergolong tinggi dibanding mangrove. Hasil analisis uji korelasi nilai indeks keanekaragaman dengan faktor abiotik menunjukkan arah positif (+) pada salinitas tanah dimana nilai R2 sebesar 0.5606 atau $50 \%$, yang artinya menunjukkan hubungan antara salinitas tanah dengan kelimpahan tumbuhan invasif di kawasan hutan pantai Balekambang sebesar 50\%. 
e-Jurnal Ilmiah BIOSAINTROPIS (BIOSCIENCE-TROPIC)

Volume 6/ No.: 1 / Halaman 46 - 53 / Agustus Tahun 2020

ISSN :2460-9455 (e) - 2338-2805(p)

\section{Daftar Pustaka}

[1] Widjaja, A. E., Rahayuningsih, Y., Rahajoe, S. J., Ubaidillah, R., Maryanto, I., Walujo, B. E., Semiadi, G. 2014. Kekinian Keanekaragaman Hayati Indonesia. LIPI Press. Bogor.

[2] Budiyono, D., Soelistyari, H. T. 2016. Evaluasi Kualitas Visual Lanskap Wisata Pantai Balekambang Di Desa Srigonco, Kabupaten Malang. Jurnal lanskap Indonesia 8 (2):80-90.

[3] Tjitrosoedirdjo, S., Tjitrosoedirdjo, S. S. Setyawati, T. 2016. Tumbuhan Invasif dan Pendekatan Pengelolaannya. Southeast Asian Regional Centre For Tropical Biology (SEAMEO BIOTROP). Bogor.

[4] Fachrul, M. F. 2012. Metode Sampling Bioekologi. Bumi Aksara. Jakarta.

[5] Southeast Asian Regional for Tropical Biology (SEAMEO BIOTROP). 2008. Invasive Alien Species Database. Akses URL:http://www.biotrop.org/database.

[6] ISSG (Invasive Species Specialist Group). 2005. Global Invasive Species Database. URL: $\mathrm{http} / / \mathrm{www}$.issg.org/database.

[7] Webber E. 2003 . Invasive Plant Species of the World : A Refererence Guide to Environmental Weeds. CABI Publishing. Cambridge.

[8] Sahira, M. 2016. Analisis Vegetasi Tumbuhan Asing Invasif Di Kawasan Taman Hutan Raya Dr. Moh. Hatta, Padang, Sumatera Barat. Skripsi. Universitas Andalas. Sumatera Barat.

[9] Setyawati, T., Narulita, S., Bahri, I.P., Raharjo, G.T. 2015. A Guide Book to Invasive Alien Plant Species in Indonesia. Research development and innovation agency ministry of Environment and Forestry. Republic of Indonesia.

[10] Abywijaya, I. K; Hikmat, A; Widyatmoko, D. 2014. Keanekaragaman Dan Pola Sebaran Spesies Tumbuhan Asing Invasif Di Cagar Alam Pulau Sempu, Jawa Timur. Jurnal biologi Indonesia $10(2): 221-235$.

[11] Ajorlo M, Abdullah R, Halim RA, Ebrahimian M. 2014. Cattle grazing effect on_Mimosa pudica L. in tropical pasture system. Pertanika Journal Tropical Agricultural Science 37(2): 249261.

[12] Yuliana, S \& Lekitoo, K. 2018. Deteksi Dan Identifikasi Jenis Tumbuhan Asing Invasif Di Taman Wisata Alam Gunung Meja Manokwari, Papua Barat. Jurnal Faloak Vol. 2 No. 2: 89102

[13] Utami, S dan Murningsih. 2018. Kenekaragaman Dan Kemelimpahan Jenis Tumbuhan Invasif di Hutan Wisata Penggaron Kabupaten Jawa Tengah. Jurnal BIOMA Vol. 20 No. 2:100-104.

[14] Soerjani M, Koestermans AJGH, Tjitrosoepomo G. 1987. Weeds of Rice in Indonesia. Balai Pustaka. Jakarta.

[15] Zayadi, H dan Hayati, A. 2017. Distribusi Spasial Pohon Peneduh Jalan Raya Lowokwaru Kota Malang dengan Aplikasi GIS. Jurnal Biosaintropis (Bioscience-Tropic)Vol. 3 No. 1: 46-52.

[16] Hood WG and Naiman RJ. 2000. Vulnerability Of Riparian Zones To Invasion By Exotic Vascular Plants. Plant Ecology 148:105-14. 